\title{
EDITORIAL
}

\section{EL DERECHO A LA EDUCACIÓN A LA LUZ DEL PRINCIPIO DE SUBSIDIARIEDAD}

\author{
THE RIgHT TO EDUCATION IN LIGHT OF THE \\ PRINCIPLE OF SUBSIDIARITY \\ O DIREITO À EDUCAÇÃO À LUZ DO PRINCÍPIO DE \\ SUBSIDIARIEDADE
}

DOI: 10.5294/DIKA.2O15.24.2.1

Los origenes del principio de subsidiariedad se remontan a las reflexiones críticas realizadas por Aristóteles en su obra Politica, ${ }^{1}$ y al comunismo defendido por Platón en su escrito República, según el cual, los hijos, las mujeres y las propiedades deberían ser comunes, es decir, compartidos por todos los miembros de la polis, de tal forma que nadie considerase ninguna cosa o persona como propia. Los reparos de Aristóteles a la propuesta de Platón se centran en que si nada pertenece a nadie, sino que todo es de todos, se haría imposible la existencia y sostenimiento de las ciudades.

El Estagirita afirma que aunque "la unidad de una ciudad en su totalidad es su mayor bien [...] sin embargo, es evidente que si el proceso de unificación avanza, ya no habrá ciudad", ${ }^{2}$ y continúa exponiendo que:

...es evidente que buscar la unificación excesiva no es mejor, pues la familia es más autosuficiente que el individuo y la ciudad más que la familia; hay voluntad verdaderamente de constituir una ciudad cuando el número de individuos forma una comunidad autosuficiente. Entonces, si es preferible el mayor grado de autosuficiencia, también es preferible lo menos a lo más unitario. ${ }^{3}$

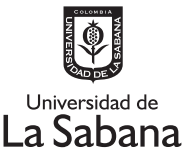

1 Aristóteles, Política, Madrid, Itsmo, 2005, pp. 128-130. 
Siguiendo el pensamiento aristotélico, autores contemporáneos como John Finnis señalan que en este principio

...la función propia de asociarse es ayudar a los participantes en la asociación a ayudarse a sí mismos o, más precisamente, a formarse a sí mismos a través de las iniciativas individuales dirigidas a elegir compromisos [...] y puesto que en las grandes organizaciones el proceso de toma de decisiones está más alejado de la iniciativa de la mayoría de esos muchos miembros que ejecutarán la decisión, el mismo principio exige que las asociaciones más grandes no asuman funciones que pueden ser realizadas eficientemente por asociaciones más pequeñas. ${ }^{4}$

De esta manera, la subsidiariedad en la comunidad politica se traduce en el deber de ayuda y protección de sus miembros por parte de las autoridades públicas. El Estado no está para servirse a sí mismo, sino para el servicio de sus ciudadanos; en otras palabras, la persona y la familia - como una asociación pequeña dentro del conjunto de la comunidad política- no están para el Estado, sino que el Estado está para ayudar a la familia y al individuo. ${ }^{5}$ Asimismo, en el documento Familiaris Consortio se advierte que en "virtud de este principio, el Estado no puede ni debe sustraer a las familias aquellas funciones que pueden igualmente realizar bien por sí solas o asociadas libremente, sino que debe favorecer positivamente y estimular lo más posible la iniciativa responsable de las familias". ${ }^{6}$ En consecuencia, todas aquellas políticas que vulneren los valores fundamentales de la familia van en contra del principio de subsidiariedad y se consideran como un abuso de autoridad del Estado.

Por otra parte, el derecho humano a la educación, contemplado en el artículo 26 de la Declaración Universal de los Derechos Humanos, constituye uno de los pilares fundamentales que garantizan el desarrollo de nuestra civilización. En el numeral tercero de dicho artículo se señala que los "padres tendrán derecho preferente a escoger el tipo de educación que habrá de darse a sus hijos". Esta disposición coincide con el principio de subsidiariedad, ya que la familia desempeña un rol primordial en la formación de sus integrantes, especialmente los menores. La aplicación de este principio radica en la autonomía de la familia, reflejada en la libertad que tienen los padres para decidir el número de sus hijos y la educación que quieren garantizarles, incluida la educación sexual. ${ }^{7}$ Constituye un derecho y un deber fundamental de los padres la educación sexual de los hijos, la cual debe realizarse bajo su supervisión, tanto en el hogar como en los centros educativos elegidos. ${ }^{8}$

4 John Finnis, Ley natural y derechos naturales, Buenos Aires, Abeledo-Perrot, 1992, p. 176.

5 Lexicón: Términos ambiguos y discutidos sobre familia, vida y cuestiones éticas, Madrid, Palabra, 2006, pp. 485-491.

6 Juan Pablo II, Familiaris Consortio, FC 45, Libreria Editrice Vaticana, 1981, en http://w2.vatican. va/content/john-paul-ii/es/apost_exhortations/documents/hf_jp-ii_exh_19811122_familiarisconsortio.html

7 Lexicón: Términos ambiguos y discutidos sobre familia, vida y cuestiones éticas, op. cit.

8 Juan Pablo II, Familiaris Consortio, op. cit., FC 37. 
En países como Argentina, Colombia, Guatemala, Mozambique, Camboya, India, Indonesia y Uzbekistán, por mencionar solo algunos, se han adoptado disposiciones legales que acogen las directrices sobre educación sexual señaladas por el Fondo de Población de las Naciones Unidas (UNFPA). Este organismo internacional trabaja con distintos gobiernos para que se implemente un tipo de educación sexual que debe ser impartida tanto en las escuelas públicas como a nivel comunitario. Para UNFPA, esta propuesta de educación

...permite a los jóvenes tomar decisiones fundamentadas sobre su sexualidad [...] Incluye información científicamente precisa sobre desarrollo humano, anatomía y embarazo, y se basa en un plan de estudios. Asimismo, incluye información sobre anticoncepción e infecciones de transmisión sexual (ITS), entre ellas el VIH [...] Los planes de estudios deben abordar también las cuestiones sociales que rodean a la sexualidad y la reproducción, entre ellas las normas culturales, la vida familiar y las relaciones interpersonales. ${ }^{9}$

Con la promoción de dichas medidas, la UNFPA busca prevenir que los jóvenes se contagien con infecciones o enfermedades de transmisión sexual y evitar los embarazos imprevistos. No obstante, un programa de educación sexual que fomenta el empleo de toda clase de anticonceptivos, que considera el aborto como un derecho reproductivo y que propone relaciones sexuales sin importar el sexo biológico de las personas, incluidas la masturbación y el sexo oral, genera gran inconformidad y preocupación en los padres, ya que estas políticas no siempre respetan sus convicciones y sus valores individuales y familiares.

Cuando en un Estado se promulga una ley que regula la educación sexual de los adolescentes bajo los parámetros señalados anteriormente, los padres tienen el derecho a exigir que los establecimientos educativos les informen sobre los contenidos teóricos y los materiales de las clases de educación sexual, para que en familia se tomen las decisiones que se consideren más apropiadas para la formación de los hijos. De lo contrario, resultaría vulnerado el principio de subsidiariedad, al ser el Estado - y no los padres- quien decide el tipo de educación sexual que deben recibir los adolescentes miembros de la familia.

No cabe duda de que la educación sexual es algo necesario, sin embargo, no son ni el Estado ni la sociedad, sino los padres, los primeros responsables de esta educación para con sus hijos. En el contexto familiar, son los progenitores quienes pueden transmitir mejor a su prole la integralidad del ejercicio de la sexualidad humana, en la cual convergen lo relacional, lo afectivo y lo espiritual.

Siguiendo este razonamiento podría concluirse que la aplicación del principio de subsidiariedad, en conjunción con el principio de neutralidad estatal, evita la instrumentalización del derecho a la educación para la difusión de ciertas ideologías

9 En http://www.unfpa.org/es/educaci\%C3\%B3n-sexual-integral\#sthash.a2FEiOsz.dpuf 
o como mecanismo de adoctrinamiento por parte del Estado a sus ciudadanos. La intervención estatal en un Estado social de derecho tiene como uno de sus limites el respeto a la autonomia de las familias para elegir el tipo de educación que desean para los hijos.

MARTHA MIRANDA-NOVOA

Editora

martha.miranda@unisabana.edu.co 